\title{
Implantação do 10S como ferramenta de gestão de qualidade em hospital
}

Nilton Cesar Pasquini ${ }^{1}$

\section{Resumo}

A implantação iniciou em fevereiro de 2011 e terminou em fevereiro de 2012. Foi criado um grupo gestor cuja função básica do gestor do programa, ou de um comitê central, é fomentar as atividades do $10 \mathrm{~S}$ por toda a empresa. A primeira atitude foi realizar uma limpeza geral (Dia D), pré-requisito para a implantação do Programa 10S. Na implantação do $10 \mathrm{~S}$ fez uso de 6 ferramentas da qualidade, sendo Diagrama de causa e efeito, Diagrama de dispersão, D5W1H, Gráficos e PDCA e Kanban. O 10S melhorou a imagem da organização perante a sociedade e órgãos governamentais. O programa disseminou no hospital a importância da prática da responsabilidade social, não só como obrigação do hospital em desenvolver ações sociais, mas como incentivo e motivação de seus próprios colaboradores para a realização de trabalhos voluntários para atender às carências da sociedade.

Palavras-chave: 10S, Gestão da qualidade, Qualidade no hospital.

\begin{abstract}
The development began in February 2011 and ended in February 2012. It was created a management group, whose basical function was to foster activities of $10 \mathrm{~S}$ across the company. The first step was to make a clean sweep (D-Day), a prerequisite for developing the 10S Program. In the development of $10 \mathrm{~S}$, we used six quality tools: cause and effect diagram, scatter diagram, 5W1H, Graphics and PDCA, and Kanban. The 10S has improved the image of the organization in society and government. The program spread in the hospital the importance of practicing social responsibility, not only as an obligation of the hospital to develop social actions, but as an incentive and motivation of its own employees to perform volunteer work to meet the needs of society.
\end{abstract}

Keywords: 10S, Quality management, Hospital management.

\footnotetext{
${ }^{1}$ Químico Industrial, MBA em Gestão e Engenharia de Qualidade, MBA em Gestão de Pessoas e Black Belt Centro Universitário Salesiano de São Paulo, Campus Maria Auxiliadora, Americana SP.

Endereço Eletrônico: nc.pasqini @ig.com.br.
} 


\section{Introdução}

O Programa 10S é um sistema de mudança comportamental de hábito e atitudes que permite criar um ambiente limpo, organizado, saudável onde o empregado sinta-se bem consigo mesmo e com os demais. É um processo estruturado para mobilizar a organização para o uso responsável dos recursos nos aspectos físicos (equipamentos, máquinas e áreas de trabalho), procedimentos e atitudes (Embrapa, 2007).

O objetivo do programa $10 \mathrm{~S}$ é tornar o nosso local de trabalho mais limpo, organizado e seguro, em que o servidor sinta-se confortável consigo e com os demais, respeitando-se a lógica de trabalho de cada um. Tudo isso, além de prover um atendimento diferenciado ao contribuinte. Contudo, para que tal ocorra é necessária uma mudança comportamental, envolvendo nossos hábitos e atitudes. A execução do programa é simples, mas exige o envolvimento de todos, em um aperfeiçoamento contínuo das rotinas de trabalho e da manutenção dos novos hábitos (Prefeitura de Votuporanga, 2012).

Os 10S são: SEIRI - Senso de Utilização, SEITON - Senso de Ordenação, SEISOH Senso de Limpeza, SEIKETSU - Senso de Saúde, SHITSUKE - Senso de Autodisciplina, SHIKARI YARO - Senso de Determinação e União, SHIDO - Senso de Treinamento, SETSUYAKU - Senso de Economia e Combate aos Desperdícios, SHISEI RINRI - Senso dos Princípios Morais e Éticos e SEKININ SHAKAI - Senso de Responsabilidade Social.

\section{Gestão da qualidade}

A gestão da qualidade em saúde tem sido um tema amplamente discutido na contemporaneidade, entre as diversas áreas e setores. Isso se deve a uma gama de fatores observados que perpassa desde questões legais, com a crescente judicialização da saúde, até questões econômicas ou relacionadas à necessidade de garantir níveis satisfatórios de segurança na prestação dos serviços em saúde (OLIVEIRA, 2009).

A preocupação com qualidade vem desde Hipócrates, mas pode-se afirmar que os primeiros modelos direcionados à gestão da qualidade da assistência médica, nos quais foi possível estabelecer uma relação com a Acreditação de hospitais, tiveram o seu início durante a Guerra da Criméia, em 1855, quando a enfermeira Florence Nightingale desenvolveu métodos de coleta de dados que objetivaram a melhoria da qualidade do atendimento prestado aos feridos de guerra. Nightingale utilizou-se de indicadores (por exemplo, taxa de 
mortalidade), para provar que, através da melhoria do controle sanitário, as mortes poderiam diminuir. Florence Nightingale revolucionou a abordagem dos fenômenos sociais demonstrando que poderiam ser objetivamente medidos, avaliados e submetidos a análises matemáticas (ROESSLER, 2006).

Segundo Mendes (2007), a qualidade dos serviços de saúde é observada quando esses serviços utilizam tecnologias efetivas, apresentam segurança para profissionais e usuários, são ofertados a partir das necessidades efetivas e de forma eficiente, em busca da eqüidade, realizam-se de forma humanizada e satisfazem as expectativas dos usuários.

Segundo o Institute of Medicine (2001), os serviços de saúde têm qualidade quando são prestados em consonância com padrões ótimos pré-definidos; são submetidos a medidas de performance nos níveis de estrutura, processos e resultados; são ofertados para atender às necessidades da pessoas; implicam programas de controle de qualidade; são ofertados em tempo oportuno; são seguros para os profissionais de saúde e para as pessoas usuárias; fazem se de forma humanizada; satisfazem às expectativas das pessoas usuárias; e são eqüitativos.

Segundo Samico (2010), a avaliação da qualidade em saúde parte de parâmetros ou atributos que vão servir de referência para a definição de qualidade e a construção de instrumentos a serem utilizados na avaliação.

Porter (2007) afirma que o desempenho do sistema de saúde só vai ser significativamente melhorado se os resultados forem mensurados e cada participante do sistema, responsabilizado pelos seus resultados. Afirma ainda que qualidade inferior não gera economia na assistência à saúde, tampouco na maioria dos outros setores. Pelo contrário, baixa qualidade leva a complicações e à necessidade de tratamentos adicionais que elevam substancialmente os custos.

As organizações de saúde são organizações profissionais, constituídas como um conglomerado de unidades independentes altamente especializadas na qual o trabalho é coordenado por ajustamento mútuo e a tecno-estrutura tem fraco poder de ingerência sobre os processos operacionais. A coordenação é processual e por resultados e a direção tem gestão indireta sobre os vários chefes de serviço (MINTZBERG, 2003).

Os estudos de desempenho hospitalar no Brasil, segundo La Forgia (2009), mostram que os hospitais brasileiros apresentam, em geral, deficiências qualitativas importantes.

Dados do BNDES mostravam que os hospitais dispunham de baixíssima capacidade gerencial. Em geral, não havia programas de qualidade utilizados, rotineiramente, nos hospitais (LIMA et al., 2009). 
O Plano de Gestão da Qualidade em Saúde surgiu como uma proposta de se avaliar, a partir dos critérios da ONA e ANVISA, o grau de incorporação das práticas de gestão da segurança, gestão por processos e gestão por resultados do conjunto dos hospitais. O Programa surgiu, enfim, de uma efetiva necessidade de medir os primeiros impactos do PROHOSP nessas instituições, no que diz respeito à gestão da qualidade (OLIVEIRA, 2009).

$\mathrm{Na}$ Europa são encontrados casos como o de Bolton Hospital Trust que pretende implementar, à semelhança do Toyota Production System, o Bolton Improving Care System. Este sistema permite obter aumentos de produtividade em vários setores e redução de tempos de espera e transição, querendo alcançar uma abrangência Lean para todo hospital e um maior envolvimento dos colaboradores na implementação Lean (Schenk, 2006).

Existem diversas formas de trabalhar conceitos de qualidade, como os programas $5 \mathrm{~S}$ (utilidade, ordenação, limpeza, saúde e autodisciplina), o PDCA (ciclo constituído de quatro fases - planejar, executar, verificar e atuar - que trata do gerenciamento pelas diretrizes) o desenvolvimento de ciclos de melhoria, a determinação de metas e a utilização de indicadores (Bittar, 2001).

\section{Metodologia}

A implantação iniciou em fevereiro de 2011 e terminou em fevereiro de 2012. Foi criado um grupo gestor cuja função básica do gestor do programa, ou de um comitê central, é fomentar as atividades do $10 \mathrm{~S}$ por toda a empresa. Para tanto, o gestor deve conhecer profundamente os conceitos, e ter uma capacidade de liderança devidamente reconhecida. Ele é responsável pela elaboração do plano diretor pelo treinamento das pessoas que irão liderar o processo de implantação nos diversos ambientes e pela própria promoção integrada do $10 \mathrm{~S}$ (SILVA et al., 2008).

Criou um plano de treinamentos para todos os níveis hierárquicos sobre a melhoria de qualidade, administração participativa, incremento de eficiência, eliminação do desperdício, melhoria no ambiente de trabalho, otimização de espaço, prevenção de acidentes, mudança de comportamento e hábito, melhoria nas relações humanas, espírito de equipe, autodisciplina, eliminação do stress das pessoas, padronização dos processos, confiabilidade dos dados de controle, redução/eliminação das condições inseguras, redução/eliminação dos atos inseguros, prevenção da poluição e motivação das pessoas (SILVA et al., 2008), aumento da produtividade e resultados e colaboradores compromissados com os resultados da empresa. 
O autor do artigo atuou como Black Belt, foi gestor responsável pelos treinamentos. A manutenção do programa foi feita através de inspeções e certificação dos sensos. Para fazer tal avaliação, foi preenchida uma check list em que constavam perguntas para cada senso de modo a quantificar a avaliação da área. Foram elaboradas perguntas referentes a cada senso (PASQUINI, 2012) (Gráfico 1).

A primeira atitude foi realizar uma limpeza geral (Dia D), pré-requisito para a implantação do Programa 10S. Este evento é de suma importância, devido a ser um marco do início do 10S. Na implantação do 10S fez uso de 6 ferramentas da qualidade, sendo Diagrama de causa e efeito, Diagrama de dispersão, D5W1H, Gráficos e PDCA (PASQUINI, 2012) fez uso também do kanban.

Antes do Dia D, foi fotografado todos os departamentos para fazer uma comparação de antes e depois, foi evitado fotografar funcionários ou objetos que os identifique a fim de evitar constrangimento. O registro fotográfico e/ou filmagem é de fundamental importância durante todo o processo de implantação, pois é a melhor forma de evidenciar os diversos estágios, motivando a equipe a persistir em busca de uma melhoria contínua, e de incentivar outras áreas que ainda não deflagraram o processo (Silva et al., 2008).

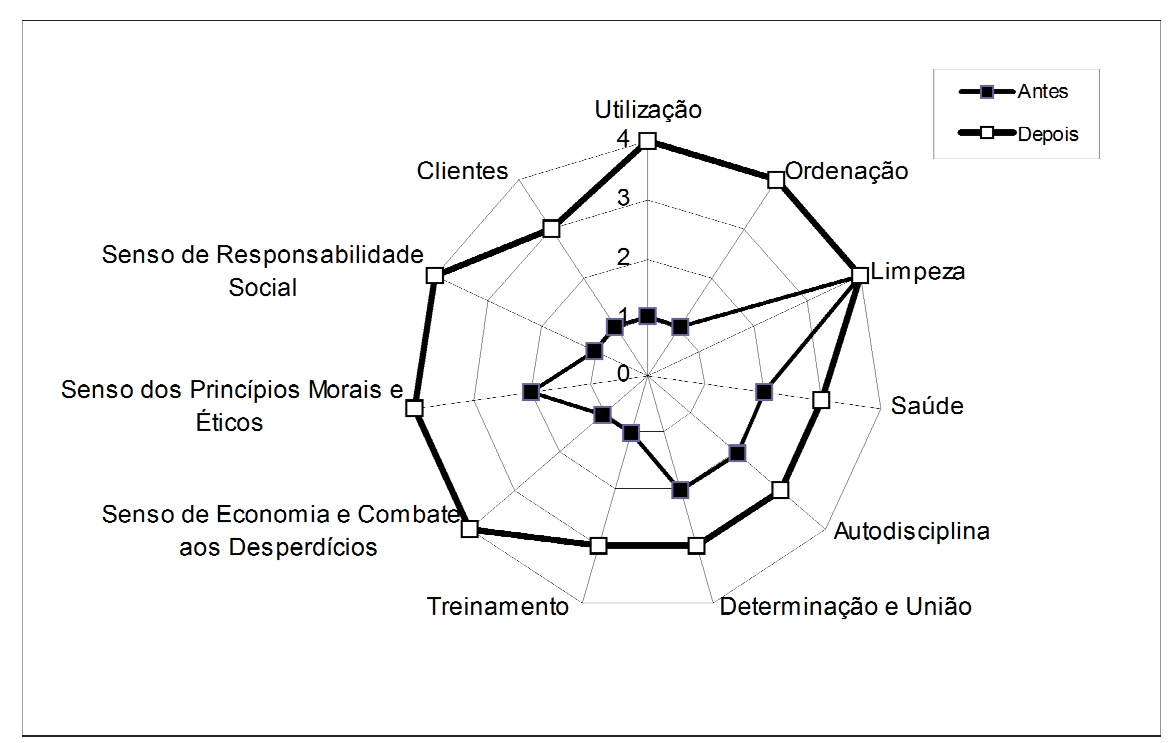

Gráfico 1. Pesquisa antes e depois da implantação do 10S, realizado 12 meses após o inicio.

Foi realizado uma auditoria antes da implantação, entrevistado alguns colaboradores e clientes, fornecido uma pontuação para cada pergunta, 0 ruim, 1 regular e 2 bom. Através desta pontuação gerou a pontuação final, sendo 0 ruim (nenhum item atende ao padrão), 1 regular (poucos itens atendem ao padrão), 2 bom (muitos itens atende ao padrão) e 3 excelente (todos os itens atendem ao padrão). Esta mesma auditoria, com as mesmas perguntas foram realizadas à 3, 6, 9 e 12 meses após a implantação. 
Segundo Yin (2005), a metodologia de estudo de caso se presta para pesquisas que procuram respostas a perguntas do tipo "como" e "por que", quando a ênfase se encontra em fenômenos inseridos em algum contexto da vida real. O estudo de caso é adequado para analisar condições contextuais, caso sejam pertinentes ao fenômeno em estudo (YIN, 2005). A vantagem de estudos de caso realizados pela coleta de dados a partir da observação participante é a oportunidade de se perceber a realidade do ponto de vista de alguém de "dentro" do estudo de caso para proporcionar um retrato acurado do fenômeno analisado (YIN, 2005).

\section{Resultados}

Foram criados e divulgados a Politica da Qualidade, Politica Ambiental, Missão, Visão e Valores, colocado em quadros e fixado em vários pontos do hospital.

Vários autores (MENDES, 1994; ANTUNES, 2000; OLIVEIRA, 2011) afirmam que o diagnóstico das condições do hospital, realizado por todos os profissionais implantados na comunidade organizacional, é primordial antes da implantação de programas de qualidade, pois permite colher informações que poderão ser mensuradas no decorrer do projeto, como também, identificar os problemas que devem ser discutidos e trabalhados prioritariamente. Mais de 95\% dos problemas foram solucionados através do PDCA. O ciclo PDCA (Plan, Do, Check e Action) compreende as seguintes etapas: "P" - planejamento de objetivos e metas a serem alcançadas; "D" - execução/realização das atividades propostas; "C" - checagem das atividades realizadas com relação ao planejado; e "A" - ação, representada pela consolidação dos resultados e correção dos erros/desvios que possam ocorrer (BOHOMOL, 2006).

As entrevistas junto aos clientes foram realizadas por abordagem, os pesquisadores abordaram em cada etapa 400 clientes (Gráfico 1).

\section{Dia D}

O Dia D é uma ocorrência muito importante para que se comece a implantação dos $10 \mathrm{~S}$ com sucesso, este dia foi causador de perspectivas, através de ferramentas de marketing como adesivos, concursos, faixas, gincanas e gibis.

Para realização desta faxina, foi necessária a troca de colaboradores entre departamentos. O departamento que causou espantou foi o armazém, por conter os seguintes fármacos vencidos: 3487 comprimidos de sulfadiazina, 2184 comprimidos de Butilbrometo de escopolamina+Dipirona sódica, 1597 ampolas de glicose, 647 comprimidos de 
amoxacilina $500 \mathrm{mg}, 365$ comprimidos de omeprazol, 349 vidros de soro fisiológico, 285 comprimidos de diclofenaco de potássio, 206 comprimidos de diclofenaco de sódio,126 vidros de dipirona, 83 vidros de paracetamol, 59 comprimidos de metildopa, 56 comprimidos de ciprofloxacino, etc.

Havia também estoque exagerado como o medicamento Furosemida (3655 comprimidos), Cloridrato de Metoclopramida (12294 ampolas), Tobramicina colírio (834 vidros), etc.

No armazém e na farmácia fez muito uso da ferramenta Kanban. Para Granban (2009) Kanban nos hospitais é um complemento ao standard work, 5S e visual management, para uma melhor gestão dos materiais em estoque.

As vantagens do kanban para artigos em estoque são: evitar estoques excessivos, erros nos pedidos, acompanhe e gerencie o fluxo de trabalho e a expiração dos prazos de validade.

\section{Meta da empresa}

A implantação do programa ... como uma meta institucional foi considerada como um fator facilitador por quase todas as participantes. Para que uma mudança seja bem sucedida há a necessidade da presença de três condições: o forte apoio da administração superior na implantação; o envolvimento de toda a organização em cada um de seus aspectos e o aperfeiçoamento de todas as atividades que não estiverem sendo realizadas conforme preconizado inicialmente (LACOMBE; HEILBORN, 2003).

\section{Mudança de cultura}

A cultura também decorre do histórico da formação das instituições de saúde. Os hospitais nasceram baseados na religiosidade, na filantropia, na beneficência e no militarismo, o que tornou as decisões tipicamente empresariais uma dificuldade por vezes intransponível. Segundo Lima e Bressan (2003), as mudanças que mais transformam a organização como um todo são as mudanças radicais, aquelas que ocorrem a partir do questionamento e da modificação da missão, da natureza e do objetivo da organização e envolvem certa ruptura de padrões de ação e pensamento, levando a um redirecionamento orientado pela busca de coerência com as contingências vigentes do contexto organizacional.

Devido a essa tendência à inércia, elas resistem à mudança, não se adaptam gradualmente à evolução do ambiente e, eventualmente, é necessário que nelas ocorra a mudança radical (DEMERS, 2007). 


\section{Geral}

$\mathrm{Na}$ troca de médico, o que estava saindo, saia muitas vezes 30 minutos antes, enquanto o que estava entrando atrasava até 1 hora, não havia qualquer controle.

O $10 \mathrm{~S}$ teve como foco principal, seus clientes, e toda reclamação era discutida pelo grupo em forma de $5 \mathrm{~W} 1 \mathrm{H}$. A centralização do processo de qualidade no paciente se constitui numa estratégia porque concilia os esforços de se entender suas necessidades com os sistemas que apoiam a melhoria contínua da qualidade dos serviços, terminando com a soberania do médico que, muitas vezes, determina que a qualidade só pode ser entendida e definida por ele (MEZOMO, 2001). Observa-se no gráfico 1, que todos os itens avaliados melhorou significativamente, a satisfação dos clientes que antes era 1 passou para 3 , sendo o máximo 4 pontos. O diretor do hospital não permitiu a publicação de qualquer referencia que pudesse identificar a organização.

\section{Dificuldade}

A maior dificuldade enfrentada na implantação do $10 \mathrm{~S}$ foi integrar os médicos, $43 \%$ eram claramente contra, $47 \%$ afirmavam ser a favor, mas não cumpriam as regras, apenas $10 \%$ se dedicavam ao projeto.

O profissional médico, sem vínculo integral com a instituição, tende a considerar a idéia da qualidade como mais um modismo e que, portanto, não merece a sua atenção. Independentemente deste aspecto, o viver de plantões e o trabalho em dois ou mais empregos - comum em várias categorias da saúde - dificultam a construção da cultura para a qualidade (BITTAR, 2004).

Alguns colaboradores seguiram os médicos, o atendimento na recepção e na coleta de sangue piorou drasticamente. Estes fatos foram observados 15 dias após o Dia D. Até aquele momento não fora citado ou insinuado algo sobre advertências. Foram realizados 10 reuniões em 24 horas com todos os colaboradores, o diretor do hospital e parte jurídica da prefeitura estavam presente para explicar os benefícios do programa novamente e a possível punição que acarretaria ao colaborador que não cumprisse as normas do programa.

Os membros de todas as profissões tendem a impor aos seus pares um conjunto de códigos de comportamento e padrões de desempenho supostamente aceitáveis, e se recusam, como regra, a aceitarem avaliações de pessoas externas. É o caso dos médicos que resistem às tentativas de empresas de assistência médica e das operadoras de planos de saúde no sentido de estabelecer normas sobre a prática da medicina (BITTAR, 2004). 
Ao longo do tempo, no decurso do processo de implantação, o comportamento dos funcionários passou a ser surpreendente, notadamente no aspecto da disposição psicológica de trabalhar-se em equipe. Isso ainda é ratificado pelos resultados positivos obtidos em relação aos itens: qualidade, ambiente interativo de trabalho, relações de trabalho entre os envolvidos, colaboração, flexibilidade para aceitar-se novas posturas no trabalho (COSTA, REIS, ANDRADE, 2005).

\section{SEIRI - Senso de Utilização}

Chiavenato (2005) afirma que guardar ou armazenar qualquer coisa desnecessária significa estoques que ocupam espaço físico e custa dinheiro.

Foi descartado 452 kilos de papel, 12 cadeiras, 4 mesas, 4 ventilador de chão, 6 impressora, 92 canetas que não funcionava, 26 porta-teco, 25 almofada de carimbo, 19 carimbos, 6 esfigmonômetro, 6 otoscópio e 2 desfibrilador.

Foram colocados a disposição 2391 clips, 37 caixas de grampo, 18 grampeador, 16 furador, 14 borracha, 13 lapiseira, 13 prancheta, 10 estilete, 9 tesoura, 6 cadeira, 4 mesa e 2 luminária de mesa.

Tornou mais visíveis os materiais realmente utilizados, assim gasta menos tempo procurando e consequentemente aumenta a produtividade. $\mathrm{O}$ ambiente ficou mais claro, confortável e fácil de limpar. Evita a compra desnecessária de materiais.

\section{SEITON - Senso de Ordenação}

De acordo com Chiavenato (2005) todos materiais devem ter seu lugar previamente estabelecido, sendo que os mais utilizados devem estar localizados em local de fácil acesso.

Neste S os colaboradores aprenderam como e onde guardar as coisas, definir lugar e modo adequados de guardá-las, padronizar os nomes dos objetos e criar um sistema de identificação visual. Assim racionalizou espaço, onde passou a sobrar 2 arquivo de 4 gavetas, sendo que havia no departamento de compra, requisição para adquirir 1 arquivo. Criou-se os padrões de máquinas e mão-de-obra.

Contribui para manter o bom estado de materiais, pois aumentou 42,3\% (médias de 6 meses) as requisições de solicitação da manutenção aos equipamentos e prédio. 


\section{SEISOH - Senso de Limpeza}

Kalkmann (2002) afirma que os benefícios deste senso são em promover satisfação e motivação para os colaboradores em trabalhar em um ambiente limpo, equilíbrio físico e mental, além de proporcionar uma imagem positiva perante os clientes.

O hospital não tinha problema de limpeza, mas havia alguns corredores com o piso muito danificado, onde foi efetuada a troca.

\section{SEIKETSU - Senso de Saúde}

Segundo Kalkmann (2002) torna-se necessário praticar os três sensos citados anteriormente, de acordo com o autor os princípios mantidos pelos sensos anteriores contribuem para a prevenção das condições que podem ser prejudiciais à saúde, como a eliminação de fontes de perigo e enfatizando as normas de segurança.

Neste item foi conscientizado que é um procedimento errado ir trabalhar usando o jaleco, que é errado sair do departamento para ir a cantina com o jaleco. Foi realizadas palestras focando os perigos que poderiam estar causando aos clientes, sobre tudo infecção hospitalar. Antonello, Godoy e Radharmana (1998) implantaram os 5S para prevenir e controlar as infecções hospitalares.

\section{SHITSUKE - Senso de Autodisciplina}

Neste item conseguimos que os médicos fossem mais rigorosos com horário. Conscientizamos os colaboradores a não esconder erros, tomar providências perante os erros. Ocorreu a padronização na recepção, no estoque. Os estoques são considerados itens primordiais quando o objetivo é a redução de custos, devido a sua relevância no ciclo operacional das organizações. No Brasil, a taxa básica de juros fixada pelo governo e os juros de mercado são significativos, fazendo com que os custos de manutenção dos estoques sejam mais elevados em relação aos países desenvolvidos. Portanto, altas taxas de juros sinalizam a urgência na busca de níveis de estoques mais baixos (LIMA, 2005).

Dentre os objetivos primários que se deseja alcançar com a padronização de medicamentos estão a redução dos custos de aquisição dos produtos, a remoção de diferentes obstáculos durante os processos de compras, o estabelecimento de maiores interações com os fornecedores, a redução dos custos de produção, a diminuição dos custos de manutenção dos produtos em estoques e a facilitação dos procedimentos de armazenagem e manuseio dos medicamentos, propiciando vantagens à instituição hospitalar como um todo (BARBIERI; MACHLINE, 2006). 
Contudo, os profissionais médicos muitas vezes se opõem à padronização de medicamentos, em função de interesses pessoais, sem a preocupação com a gestão dos custos hospitalares (MCKEE; HEALY, 2000).

Contudo, devemos lembrar que preferências por um determinado medicamento ou grupo de produtos, por parte dos médicos, e as pressões exercidas pela indústria farmacêutica sobre os responsáveis pelas aquisições de remédios, são as maiores barreiras encontradas para a padronização de medicamentos em hospitais, ocasiões em que, nem sempre, são respeitados os princípios éticos vigentes (MCKEE; HEALY, 2000).

O padrão não é fixo, algo que nunca deve ser mudado, ele pode e deve ser melhorado para a obtenção de melhores resultados. Mas esta mudança não deve ser aleatória e a esmo, mas deve comunicar o responsável e sugerir a mudança.

Ter Senso de Autodisciplina é desenvolver o hábito de observar e seguir normas, regras, procedimentos, atender especificações, sejam elas escritas ou informais, é criticar de forma construtiva e recebê-las sem tomar como algo pessoal.

\section{SHIKARI YARO - Senso de Determinação e União}

De acordo com Senge (2000), a maioria das empresas precisa sofrer uma mudança cultural para que as pessoas passem a compartilhar conhecimentos que mantêm guardados a sete chaves. Para que essa partilha seja relevante, ela deve estar alinhada às estratégias organizacionais.

Portanto, trabalhar em equipe implica um senso de missão compartilhada e responsabilidade coletiva (DAFT, 2010).

Neste senso o projeto conseguiu melhorar as relações interpessoais e maior compromisso dos colaboradores com a busca de resultados, mas não aumentou a confiança dos colaboradores perante a organização e não contribuiu para reter talentos.

\section{SHIDO - Senso de Educação}

O projeto focou em treinamento, desenvolvimento e educação (TD\&E), mais ênfase em desenvolvimento e educação. O projeto seguiu Borges-Andrade (2002), onde TD\&E pode ser visto como um sistema composto por três subsistemas: avaliação de necessidades; planejamento e sua execução e avaliação do treinamento. $\mathrm{O}$ organização fez parceria com um hospital escola. 


\section{SETSUYAKU - Senso de Economia e Combate aos Desperdícios}

Doze meses após o dia D não havia vencido qualquer medicamento.

Foi realizado PDCA para reduzir consumo de oxigênio para inalação, produtos na lavanderia, água, energia elétrica e roupa de cama; tiveram redução respectivamente de 12,3\%; 27,5\%, $9,3 \% ; 11,6 \%$ e $29,4 \%$.

Aplicou o PDCA no restaurante, onde a sobra não aproveitáveis estava em 6\%. De acordo com Vaz (2006) admite-se como aceitáveis percentuais de até $3 \%$ ou de 7 a $25 \mathrm{~g}$ por pessoa. Concluiu o PDCA com 3,7\% de sobra não aproveitáveis.

\section{SHISEI RINRI - Senso dos Princípios Morais e Éticos}

A ética é ainda indispensável ao profissional porque, na ação humana, o "fazer" e o "agir" estão interligados. O "fazer" diz respeito à competência, à eficiência que todo profissional deve possuir para exercer bem a sua profissão. $\mathrm{O}$ "agir" refere-se à conduta do profissional, ao conjunto de atitudes que deve assumir no desempenho de sua profissão (Abba, 2012).

Aqui o projeto atuou com os colaboradores na lealdade e respeito no trato com clientes, colegas e superiores. Realizou 3 palestras e 5 dinâmica, nas dinâmicas fez os colaboradores sentirem a frustação de não respeitarem seus princípios morais e éticos.

Nos anos de 2009 e 2010 o hospital registrou 17 queixa de assédio sexual e 22 de assédio moral, após o inicio da implantação dos 10Ss em fevereiro de 2011, foi registrado 2 queixa.

Através deste senso educamos muitas enfermeiras e agentes de limpeza a não mais usar calça branca transparente. Foi definido padrão de conduta para os colaboradores, criando compromisso dos mesmos com suas atitudes e comportamento.

\section{SEKININ SHAKAI - Senso de Responsabilidade Social}

Segundo Ashey (2002) pode ser interpretado como um compromisso assumido pelas instituições junto a sociedade onde se inserem, e que pode ser expresso por meio de práticas que afetam de forma positiva, abrangendo-a amplamente, ou a alguma comunidade, de modo específico, de maneira proativa e ética no que diz respeito a sua função social e sua prestação de contas para com ela.

O item estabeleceu e difundiu boas práticas de atendimento, ressaltando os compromissos com a sociedade, oferecer tratamento humanizado, valorizando o ser humano e priorizando a qualidade de vida. 
O hospital criou programas como: Contadores de histórias, Xoxo dodói, Vida dura (voltado para prostitutas) e mães que são pais.

\section{Conclusões}

O processo de implantação não foi ortodoxo uma vez que a referida organização possui peculiaridades por ser um hospital, daí haver optado por fazer adaptações no sistema teórico do 10S. As adaptações referidas foram de exclusiva responsabilidade do Black Belt do programa, o qual se responsabilizou, correndo os riscos do sucesso ou do fracasso.

O trabalho demonstra a viabilidade e os aspectos favoráveis da utilização de processos gerenciais específicos na administração da farmácia hospitalar. Observou-se que os processos descritos são implementados rapidamente, caso estejam disponíveis elementos facilitadores, como sistemas computacionais, a tecnologia da informação e pessoas comprometidas com o sucesso do projeto (NOVAES, GONÇALVES, SIMONETTI, 2006).

O 10S melhorou a imagem da organização perante a sociedade e órgãos governamentais. O programa disseminou no hospital a importância da prática da responsabilidade social, não só como obrigação do hospital em desenvolver ações sociais, mas como incentivo e motivação de seus próprios colaboradores para a realização de trabalhos voluntários para atender às carências da sociedade.

\section{Referências Bibliográficas}

ABBA. Ética no trabalho. Disponível em: http://www.abba.org.br/arquivos/projeto_ester/ETICA_NO_TRABALHO.pdf. Acessado em $17 / 08 / 2012$.

ANTONEllO, N., R., B.; GODOY, L., P.; RADHARAMANAN, R. O programa 5S`S utilizado na prevenção e controle das infecções hospitalares. Disponível em: http://www.abepro.org.br/biblioteca/ENEGEP1998_ART429.pdf. Acessado em: 13/18/2012.

ANTUNES, A. V; TREVIZAN, M. A. Gerenciamento da qualidade: utilização no serviço de enfermagem. Rer. Latino-Am Enferm. 2000;8(1):35-44.

ASHLEY, P. A. ética e responsabilidade social nos negócios. São Paulo, Saraiva, 2002.

BARBIERI, J. C.; MACHLINE, C. Logística hospitalar: teoria e prática. São Paulo: Saraiva, 2006. 326 p. 
BITTAR, V. N. J. O. Cultura \& Qualidade em hospitais. Disponível em: http://ww1.ellubrasil.com.br/sites/ellubrasil.w20.com.br/files/03__cultura_e_qualidade_em hospitais.pdf. Acessado em : 12/08/2012.

BOHOMOL, E. Padrões para avaliação da qualidade da assistência de enfermagem. In: D’innocenzo M, coordenadora. Indicadores, auditorias, certificações: ferramentas de qualidade para gestão em saúde. São Paulo: Martinari; 2006. p. 73-85.

CHIAVENATO, I.. Administração de Produção: uma abordagem introdutória. Rio de Janeiro. Elsevier, 2005.

COSTA, R. B. F.; REIS, S, A.; ANDRADE, V., T. Implantação do programa 5S em uma empresa de grande porte: importância e dificuldades. ENEGEP, XXV Encontro Nac. de Eng. de Produção - Porto Alegre, RS, Brasil, 29 out a 01 de nov de 2005. Disponível em: http://www.abepro.org.br/biblioteca/ENEGEP2005_Enegep0201_0820.pdf. Acessado em: $12 / 08 / 2012$.

DAFT, R. L. Administração. Tradução por Harue Ohara Avritcher. São Paulo : Cengage Learning, 2010.

DEMERS, C. Organizational change theories: a synthesis. Thousand Oaks, California: Sage Publications, 2007.

EMBRAPA. Cartilha 10S. Programa 10S: Orientação para implementação. 2007. Disponível em: http://www.cnpsa.embrapa.br/sgc/sgc_publicacoes/publicacao_x1i84m4h.pdf. Acessado em: 20/08/2012.

INSTITUTE OF MEDICINE. Crossing the quality chasm: a new health system for the $21 \mathrm{st}$.

Century. Washington, The National Academies Press, 2001

Lacombe F, Heilborn G. Administração: princípios e tendências. São Paulo: Saraiva; 2003.

LIMA, H. O . A avaliação dos hospitais PRO-HOSP no $1^{\circ}$ Prêmio Célio de Castro - Edição 2008. Trabalho apresentado no IX Congresso Internacional de Qualidade em Serviços e Sistemas de Saúde, Rio de Janeiro, 2009.

LIMA, M.P. Estoque: custo de oportunidade e impactos sobre os indicadores financeiros. Centro de Estudos em Logística - CEL - COPPEAD - UFRJ, Rio de Janeiro, RJ, 2003. Disponível em: http://www.cel.coppead.ufrj.br/fs-busca.htm?fr-monitor . Acessodo em 20/07/2012.

LIMA, S.M.V. e BRESSAN, C.L. Mudança organizacional: uma introdução. In: LIMA, S.M.V. (Org). Mudança organizacional: teoria e gestão. Rio de Janeiro: Editora FGV, 2003.

MENDES, E. El futuro de los hospitales públicos: Brasil. In: Paganini JM, Novaes HM. El hospital público: tendências y perspectivas. Washington(DC): OPAS; 1994. p. 77-95. 
MENDES, E. V. Revisão bibliográfica sobre redes de atenção à saúde. Belo Horizonte:

Secretaria de Estado de Saúde de Minas Gerais, 2007. Mimeo.

MEZOMO, J. C. Gestão da qualidade na saúde: princípios básicos. São Paulo: Manole; 2001.

MCKEE, M.; HEALY, J. The role of the hospital in a changing environment. Bulletin of the World Health Organization, Geneva, v. 78, n. 6, p. 803-810, mai. 2000.

MINTZBERG, H. Criando organizações eficazes: estruturas em cinco configurações. São Paulo: ATLAS; 2003.

OLIVEIRA A. E. M, MALIK AM. Avaliação de resultados. In: Malik AM, Vecina Neto G. Gestão em saúde. Rio de Janeiro: Guanabara Koogan; 2011. p. 138-43.

NOVAES, M. L. O.; GONÇALVES, A. A.; SIMONETTI, V. M. M. Gestão das farmácias hospitalares através da padronização de medicamentos e utilização da curva ABC. XIII SIMPEP - Bauru, SP. Disponível http://www.simpep.feb.unesp.br/anais/anais_13/artigos/962.pdf. Acessado em: 14/08/2012.

OLIVEIRA, B. R. Processo e metodologia no Prêmio Célio de Castro: uma análise pontual da política de gestão da qualidade hospitalar em Minas Gerais. RAHIS - Revista de Administração Hospitalar e Inovação em Saúde - Ano 2, No3, jul./dez. 2009.

PORTER, M. E., TEISBERG, E. Repensando a saúde: estratégias para melhorar a qualidade e reduzir os custos. Porto Alegre: Bookman, 2007.

PREFEITURA DE VOTUPORANGA. Manual de orientação Programa 10S. Disponível em: http://www.votuporanga.sp.gov.br/secretarias/administra/10s/manual_10s.pdf. Acessado em 20/08/2012.

ROESSLER, I. F. Treinamento em avaliação de serviços, licenciamento sanitário e acreditação: multiplicadores: acreditação: módulo 4. Brasília: Organização Nacional da Acreditação, 2006.

SAMICO, I. Avaliação em Saúde: Bases conceituais e operacionais. Rio de Janeiro: MedBook, 2010.

SENGE, P. A quinta disciplina: Caderno de Campo: estratégias e ferramentas para construir uma organização que aprende. Rio de Janeiro: Qualitymark, 2000. 